\title{
Mechanisms Targeting the Unfolded Protein Response in Asthma
}

Sanaz Dastghaib, Ph.D. ${ }^{1,2}$, P. Sravan Kumar, M.Sc. ${ }^{3}$, Sajjad Aftabi, M.Sc. ${ }^{4,5}$, Gautam Damera, Ph.D. ${ }^{6}$, Azadeh Dalvand, M.Sc. ${ }^{4}$, Adel Sepanjnia, M.Sc., Mohammad Kiumarsi, B.Sc. ${ }^{4}$, Mohamad-Reza Aghanoori, Ph.D.7,15, Sukhwinder Singh Sohal, Ph.D. ${ }^{8}$, Sudharsan R. Ande, Ph.D. ${ }^{9}$, Javad Alizadeh, M.Sc. ${ }^{4,10}$, Pooneh Mokarram, Ph.D. ${ }^{1,2}$, Saeid Ghavami, Ph.D. 2,4,9,11*, Pawan Sharma, Ph.D. ${ }^{12 *}$, Amir A. Zeki, M.D. ${ }^{13,14 * \$}$

${ }^{1}$ Department of Clinical Biochemistry, School of Medicine, Shiraz University of Medical Sciences, Shiraz Iran.

${ }^{2}$ Autophagy Research Center, Health Policy Research Center, Institute of Health, Shiraz University of Medical Sciences; Shiraz, Iran

${ }^{3}$ National Institute of Pharmaceutical Education \& Research, Hyderabad, TA, 500037, India

${ }^{4}$ Department of Human Anatomy and Cell Science, Rady Faculty of Health Sciences, Max Rady College of Medicine, University of Manitoba; Winnipeg, Canada

${ }^{5}$ Medical Physics Department, Cancer Care Manitoba, University of Manitoba, Canada

${ }^{6}$ Personalized and Predictive Medicine (Respiratory), Global R\&D Teva Pharmaceuticals, Malvern, PA-19355, USA

${ }^{7}$ Division of Neurodegenerative Disorders, St Boniface Hospital Albrechtsen Research Centre, and Department of Pharmacology and Therapeutics, University of Manitoba, Winnipeg, Manitoba, Canada 
${ }^{8}$ Respiratory Translational Research Group, Department of Laboratory Medicine, College of Health and Medicine, University of Tasmania, Launceston, Tasmania, Australia, 7248

${ }^{9}$ Department of Internal Medicine, University of Manitoba, Winnipeg, Canada

${ }^{4,10}$ Research Institute of Oncology and Hematology, Cancer Care Manitoba, University of Manitoba, Winnipeg, Canada

${ }^{11}$ Biology of Breathing Theme, Children Hospital Research Institute of Manitoba, University of Manitoba; Winnipeg, Canada

${ }^{12}$ Center for Translational Medicine, Thomas Jefferson University, Philadelphia, PA USA 19107

${ }^{13}$ University of California, Davis School of Medicine. Department of Internal Medicine. Division of Pulmonary, Critical Care, and Sleep Medicine. U.C. Davis Lung Center, Davis, CA.

${ }^{14}$ Veterans Affairs Medical Center, Mather, CA.

${ }^{15}$ Department of Human Genetics, School of Medicine, Shiraz University of Medical Sciences, Shiraz Iran

\section{*Contributed equally}

\section{${ }^{\$}$ Correspondence}

Amir A. Zeki, M.D.

Associate Professor

University of California, Davis

CA, USA

E-Mail: aazeki@ucdavis.edu 


\section{Running title: UPR in asthma}

Authors' contribution: SG, AAZ and PS conceived the review. All authors contributed equally in writing the review and approved the final version.

Supported by: U.C. Davis PI Bridge Fund (AAZ), Rebecca Cooper Research Foundation (PS), Research Manitoba New Investigator Operating grant (SG).

Conflict-of-interest statement: The Authors have no conflict of interest.

\section{Abbreviations:}

4-PBA: bba4-phenyl butyric acid, AEC: Airway Epithelial Cell, AGR2: Anterior Gradient 2, AHR: Airway Hyper-Responsiveness, APC: Antigen-Presenting Cell, ARG2: Arginase 2, ASL: Airway Surface Liquid, ASM: Airway Smooth Muscle , ATF4: Transcription Factor 4, ATF6: Activating Transcription Factor 6, BAX: BCL2-Associated X Protein, C/EBP: CCAAT/enhancer-binding Protein, CHOP: CCAAT/enhancer-binding Protein (C/EBP) Homologous Protein, COPD: chronic obstructive pulmonary disease, CS: cigarette smoke, DC: Dendritic Cell, eIF2 $\alpha$ : Eukaryotic Translation Initiation Factor $2 \alpha$, ER: Endoplasmic Reticulum, ERAD: ER-associated Degradation, ERp57: ER Resident Protein 57, FeNO: fraction of exhaled nitric oxide, GCM: Goblet Cell Metaplasia, GRP78: 78-kDa Glucose-Regulated Protein, GWAS: Genome-wide Associated Studies, HDM: House Dust Mite, HRV: Human Rhinovirus, IPF: idiopathic pulmonary fibrosis, IgE: Immunoglobulin E, IL13: Interleukin, IRDD: IRE1-

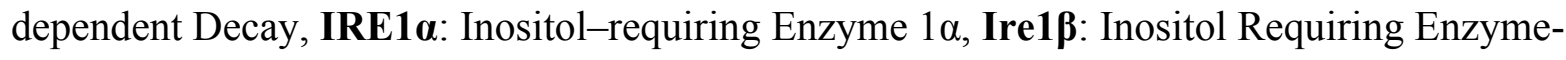
1beta, JNK: c-Jun NH2-termina Kinase, miRNA: microRNA, MUC 5AC: Mucin 5AC, NF-kß: Nuclear Factor kappa B, NO: Nitric Oxide, Nrf2: Nuclear Factor Erythroid 2-related Factor 2, 
ORMDL3: Orosomucoid like 3, PDIA5: Protein Disulfide Isomerase A5, PERK: Protein kinase RNA-like Endoplasmic Reticulum Kinase, PP1: Protein Phosphatase 1, PPP1R15A: Protein Phosphatase 1 Regulatory Subunit 15A, RIP: Regulated Intra-membrane Proteolysis, ROS: Reactive Oxygen Species, SERCA: Sarco-endoplasmic Reticulum Calcium-ATPase Pump, SNP: Single Nucleotide Polymorphism, SP: Site-1 and site 2 Protease, Th2: T helper type 2, TNF: Tumor Necrosis Factor, TUDCA: Taurohyodeoxycholic Acid, UPR: Unfolded Protein Response, VEGF: Vascular endothelial growth factor, VEGF: Vascular Endothelial Growth Factor, XBP1: X-box-binding Protein 1 


\begin{abstract}
Lung cells are constantly exposed to various internal and external stressors that disrupt protein homeostasis. To cope with these stimuli, cells evoke a highly conserved adaptive mechanism called the unfolded protein response (UPR). UPR stressors can impose greater protein secretory demands on the endoplasmic reticulum (ER) resulting in the development, differentiation, and survival of these cell types to meet these increasing functional needs. Dysregulation of the UPR leads to the development of the disease. The UPR and ER stress are involved in several human conditions such as chronic inflammation, neurodegeneration, metabolic syndrome, and cancer. Further, potent and specific compounds that target the UPR pathway are under development as future therapies. The focus of this review is to thoroughly describe the effects of both internal and external stressors on the ER in asthma. Further, we discuss how the UPR signaling pathway is activated in the lungs to overcome cellular damage. We also present an overview of the pathogenic mechanisms with a brief focus on potential strategies for pharmacological interventions.
\end{abstract}

Keywords: endoplasmic reticulum, ER stress, asthma, unfolded protein response. 


\section{THE UNFOLDED PROTEIN RESPONSE (UPR)}

The "cellular stress response" is defined as the cellular changes in response to stressors such as environment, starvation, and/or cytotoxic compounds (1-3). Cellular damage activates compensating signaling pathways in all organelles to initiate the adaptive immune system, restore intracellular homeostasis, and promote cell survival (4). The focus of this review is to describe the effects of stress on the endoplasmic reticulum (ER) and the pathways activated in this vital and multi-functional organelle to overcome cellular damage in asthma (5-9).

ER stress can disturb the fine balance between cellular demand for protein biosynthesis and the ER's capability for protein folding. Various stressors can directly or indirectly induce instability in the ER microenvironment leading to ER stress. Some of these include glycosylation inhibitors (e.g. tunicamycin), hypoxia, glucose deprivation, calcium metabolism mediators, calcium ionophores (such as A23187), calcium pump inhibitors (e.g. thapsigargin), viral infections, and reducing agents (dithiothreitol and 2-mercaptoethanol) that cause changes in the oxidative state of the ER lumen and proper protein folding $(6,10-13)$. These stressors have a significant impact on the ER, leading to the accumulation of misfolded proteins in the ER lumen and the initiation of defensive mechanisms against the misfolded protein accumulation $(14,15)$. Under normal cell conditions, there is a basal level of improperly folded proteins. These proteins are returned to the cytosol and then are degraded through the cellular degradation system. However, any deficiency in the function of this degradation machinery leads to the accumulation of misfolded un-degraded proteins that are potentially toxic leading to ER stress (16-20).

ER stress triggers a cascade of cellular signaling pathways known as the unfolded protein response (UPR) (21-24). The UPR functions principally to restore intracellular homeostasis and 
proteostasis through establishing proper protein folding in the ER and activation of other pathways such as ER-associated degradation $(\operatorname{ERAD})(25,26)$ to remove unwanted proteins (unfolded/mutated/misfolded), and to inhibit translation of new proteins in order to stabilize intracellular homeostasis $(5,19,27)$. Of note, the UPR system balances the loading of incoming proteins to the ER and its protein folding capacity, allowing the cell to adapt more easily to the specific demands and any subsequent imbalances in protein handling $(28,29)$. In most cases, ER stress occurs due to pathological conditions within the cell, whereas the UPR system normally operates in specialized secretory cells in a continuous and active mode (30). The UPR also plays an important role in immune responses during the assembly of heavy chains and antibody secretion (31). Recent studies indicate that the UPR is activated in cells under both acute and prolonged stress and plays a key role in many diseases including diabetes, cancers, various immune diseases, neurodegenerative disorders, cataracts, pulmonary fibrosis, cardiomyopathy, atherosclerosis, ischemia, nephrotic syndrome, non-alcoholic steatosis, and psoriasis (32-34).

A fundamental function of the UPR is to alleviate the accumulation of unfolded proteins in the ER and to re-establish quality control and secretory proteostasis during ER stress $(29,35,36)$. The UPR controls the expression of a variety of genes involved in protein folding, secretion, and quality control. Thus, the UPR regulates ER function and other aspects of cellular physiology, such as mitochondrial biology, lipid metabolism, and intracellular apoptotic pathways.

Mitochondria, like the ER, have a specific quality control system called mitochondrial UPR (UPR $\left.{ }^{\mathrm{mt}}\right)$, which is activated by several cellular disorders $(28,32,37)$. Although the UPR has been well-studied in the ER and the cytosol, its correlation with $\mathrm{UPR}^{\mathrm{mt}}$ has not been clearly determined. The UPR ${ }^{\mathrm{mt}}$, acting as a stress response pathway, may regulate the protein folding 
capacity of the mitochondrial matrix by monitoring the load of folding proteins and signaling to the nucleus with subsequent upregulation of the respective chaperone-encoding genes, in normal physiology, as well as disease conditions. UPR ${ }^{\mathrm{mt}}$ function results in mitochondrial-nuclear (mitonuclear) communication that is an adaptive transcriptional response pathway. This signaling increases mitochondrial recovery to ensure that specific proteins are properly translated, folded, and degraded through chaperones, such as Hsp60 and mtHsp70, in the mitochondria. It can also promote proteolysis of unfolded proteins as well as glycolytic and detoxification of genes (3841).

\section{UPR arms in ER stress}

The UPR system is controlled by three ER transmembrane proteins, acting as stress sensors, as well as 78-kDa glucose-regulated protein (GRP78). The transmembrane proteins include inositol-requiring enzyme $1 \alpha(\operatorname{IRE} 1 \alpha)$, protein kinase RNA-like endoplasmic reticulum kinase (PERK), and activating transcription factor 6 (ATF6) (21, 42-44). Under physiological conditions, these sensors are inhibited by GRP78, which is bound to their luminal domains. In the event of unfolded protein accumulation, GRP78 dissociates from the ER to overcome the perturbation in protein folding due to its higher affinity for unfolded protein which is required for its release from IRE1 and PERK, and this leads to activation of the UPR signaling pathway (Figure 1).

GRP78

GRP78, is one of the significant characterized chaperones that is conserved from yeast to human with ATPase activity. GRP78 has two motifs: a signal peptide that targets GRP78 to the $\mathrm{ER}$ and a C-terminal KDEL that acts as a retention signal to the ER by changing its monomeric 
and oligomeric form. In the monomeric and unmodified structure, GRP78 is associated with unfolded peptides in the ER lumen, and it is under the influence of post-translational modification, i.e., ADP-ribosylation, in the oligomeric form. GRP78 is low at basal levels but significantly increases during ER stress, calcium homeostasis, and active UPR processes (45, 46).

GRP78 is responsible for several cellular processes: it facilitates the translocation, assembly, and folding of newly synthesized nascent proteins. It prevents misfolding and aggregation of proteins in cells and removes unfolded/misfolded proteins in the ER-associated degradation (ERAD) pathway. It also regulates calcium homeostasis via the influence of ERmitochondrial calcium crosstalk. In general, the most important role of GRP78 is to serve as a sensor, marker, and the master regulator of ER stress by its anti-apoptotic function as an ER chaperone and its ability to control the initiation of the UPR signalling pathway $(43,47,48)$.

IRE1

IRE1 is a type 1 transmembrane protein with two enzymatic features in cytosolic domains; a serine/threonine kinase and endoribonuclease function. It has two unique homologs in humans: IRE1 $\alpha$ and IRE1 $\beta$ (structurally more similar to murine IRE1 than human) (27). While IRE1 $\alpha$ is expressed ubiquitously, IRE1 $\beta$ is only expressed in pulmonary, intestinal epithelial, and mucosal epithelial tissues. Among the UPR signaling pathways, IRE1 $\alpha$ is a key sensor for regulating cells' fate. Deletion of IRE1 $\alpha$ results in embryonic lethality although previous studies have shown that IRE1 $\beta$ knock-out mice are viable. Therefore, many recent investigations in UPR pathways have been focused on the IRE1 $\alpha(49-51)$. 
Dissociation of GRP78 triggers activation of IRE1, which itself can target the X-boxbinding protein (XBP1) mRNA with its kinase and endoribonuclease activity. IRE1 $\alpha$ promotes an atypical splicing of XBP1 mRNA near the ER membrane to produce XBP1s (splice). XBP1s is a transcription factor and localizes in the nucleus to regulate the expression of several genes that are involved in the ERAD pathway, expansion of the ER compartment, protein folding, trafficking, and secretory pathways. IRE1 also promotes cell survival, i.e., inhibition of ER stress-induced apoptosis, via inhibition of CCAAT/enhancer-binding protein (C/EBP) (CHOP) $(24,32)$. Hyperactivation of IRE1 can influence c-Jun NH2-termina kinase (JNK), NFא $\beta$, and initiate the process known as IRE1-dependent decay (RIDD). This process decreases some mRNAs and microRNAs (miRNAs), including miR-17, miR-34a, miR-125b, and miR-96 (52, 53) to reduce ER protein loading.

PDIA6 is a subtype of protein disulfide isomerase in eukaryotic ER. Mammalian IRE-1 has three cysteines in its luminal domain including Cys109, Cys148, and Cys332. The PDIA6 targets Cys148, reducing the disulfide bond in the region; and consequently, increasing the inactivation of IRE-1 (or terminating) signaling. The PDIA6 acts independently on UPR signaling arms. However, during stress conditions and disrupted ER $\mathrm{Ca}^{+2}$ homeostasis, XBP1 splicing increases. Under these conditions, the $\mathrm{Ca}^{+2} / \mathrm{PDIA} 6$ crosstalk increases the IRE-1 activity that will further support ER homeostasis (54-56).

PERK

PERK is activated after separation of GRP78; and then, it is auto-phosphorylated in the Ser/Thr kinase domain, which leads to phosphorylation of eukaryotic translation initiation factor 
$2 \alpha(\mathrm{eIF} 2 \alpha)$. This results in suppression of protein translation and a significant reduction in the number of proteins entering the ER (34).

Despite its potent pro-survival role, phosphorylated eIF2 $\alpha$ can activate the translation of transcription factor 4 (ATF4). ATF4 acts as a repressor or activator of the transcription of several genes involved in key biological processes such as bone resorption, glutathione synthesis, amino acid metabolism (i.e., asparagine synthetase), resistance to oxidative stress, neovascularisation (VEGF), and ER chaperones. It can also promote DNA damage response, expression of CHOP (C/EBP homologous protein) known as growth arrest and DNA damage-inducible protein GADD34 (PPP1R15A), and pro-apoptotic BCL-2 family proteins. GADD34 dephosphorylates activated eIF2 $\alpha$ via a protein phosphatase 1 (PP1)-interacting protein and prevents its ability to inhibit translational events. PERK can also induce $G_{1}$ cell cycle arrest that is mediated by the loss of cyclin D1 via the inhibition of its translation as well as increased degradation during ER stress (57).

ATF6

Activating transcription factor 6 (ATF6) is a type 2 transmembrane protein in the ER with transcription factor activity located in its cytosolic domain. In contrast to the activation of IRE1 and PERK during ER stress, ATF6 is transported to the Golgi compartment after dissociation from GRP78 and becomes activated by regulated intra-membrane proteolysis (RIP) with site-1 and site $2(\mathrm{SP})$ protease. This leads to the translocation of the cytosolic domain $(50 \mathrm{kD})$ to the nucleus as a transcription factor; and consequently, an increase in the expression of CHOP, ER chaperones, ER quality control, and protein folding machinery, ERAD components, and XBP1. 
In addition to GRP78, protein disulfide isomerase A5 (PDIA5) and the cysteine oxidation status of ATF6 have major impacts on the activation of ATF6 $(34,58,59)$.

Activation of the ATF6 signaling pathway is targeted via oxidoreductase ERp18, which is associated with ATF6 following ER stress. It also regulates the quality of ATF6 during trafficking from the ER to the Golgi and protects the cell against prolonged ER stress. ERp18 performs a regulatory role during UPR and induction of ATF6 via reducing disulfide within the ATF6 luminal domain by masking Golgi-localization sequences in the ATF6. During ER stress, ERp18 reduces ATF6 disulfide, leading to the release of BiP from ATF6. The reduced ATF6 is then packaged into COP II vesicles to be transported to the Golgi, then the reduced ATF6 is cleaved by S1P and S2P. Following this, activated ATF6 (ATF6 N-terminal domain) translocates to nucleus to alter gene expression which is required to restore ER homeostasis $(60,61)$.

\section{ASTHMA}

Asthma is a common respiratory disease that clinically manifests as wheezing, chest tightness, dyspnea, and cough $(62,63)(63-68)$. Approximately 5-10\% of the general population is affected by asthma, and the incidence is higher among preschoolers (67). Asthma is increasingly recognized as a heterogeneous disease defined by reversible and periodic airway obstruction (i.e. swelling and narrowing of airways), mucus metaplasia/hyperplasia (i.e. increased mucus production), airway smooth muscle cell hypertrophy, and airway hyperresponsiveness (AHR). Severe asthma is approximately $5-10 \%$ of the asthma population, is difficult to manage, and is very distinct from milder forms of asthma.

Asthma can be categorized according to molecular phenotypes of type 2 and non-type 2 inflammation (69), may be allergic or non-allergic in origin $(62,66,67,70)$, and is associated 
with both genetic and environmental factors $(67,70)$. Allergic asthma is the most common type of asthma where allergens induce eosinophilia and T helper type 2 (Th2 or type 2) inflammatory responses $(62,65)$. Exposure to environmental factors, such as house dust mite (HDM), pollen, animal dander, fungi, air pollution, and viral or bacterial infection are identified as asthma triggers $(62,71)$. Corticosteroid-resistance is a hallmark of some forms of severe asthma, where neutrophilic and non-type 2 inflammation can also predominate (62).

\section{Histopathology of Asthma}

Airway epithelial cells (AECs) form a physiological mucosal barrier (the airway epithelium) between the lungs and the external environment (64). The AECs consist of different cell types (e.g. club cells (Clara cells), mucus-producing cells, basal cells, etc.), form apical junction complexes and produce an airway surface liquid (ASL) layer (72). The epithelium can initiate and control various immune and inflammatory responses that are induced by allergens, various infectious agents, and pollutants $(72,73)$. Other resident airway cells crosstalk with the epithelium and play an integral part in the pathophysiology of asthma including airway smooth muscle (ASM) cells, submucosal mucus glands, resident immune cells, and the vasculature.

Various indoor and outdoor stimulants can alter epithelial cell fate by activation of specific receptor groups on the AEC surface which initiates downstream intracellular signal transduction cascades $(64,72,74)$. Activation of AECs induces the secretion of manifold inflammatory cytokines and growth factors (64) relevant to asthma pathogenesis. Certain inflammatory cytokines such as interleukin-13 (IL13) can disrupt the integrity and functionality of airway cells, leading to impaired cell function, and adverse tissue remodeling (72). In addition to the activation of innate lymphoid cells, $\mathrm{T}$ cells, dendritic cells, and inflammatory cell 
recruitment, adverse airway remodeling including AEC thickening, goblet and mucus cell metaplasia, basement membrane thickening, and ASM hypertrophy and hyperplasia all contribute to bronchoconstriction and AHR (69). Additionally, mucus gland hypertrophy and proliferation of airway blood vessels (induced by vascular endothelial growth factor (VEGF)) can lead to further airway narrowing (73).

\section{Onset and Progression of Asthma}

Asthma can be triggered by various environmental aeroallergens and stimuli that activate Th2 lymphocytes leading to the accumulation of mast cells, secretion of inflammatory mediators, and the infiltration of eosinophils, neutrophils, and macrophages (64, 71, 74). Pulmonary alveolar macrophages (AM) extend from alveolar space to the upper airways. AMs are activated in response to direct allergen exposure such as HDM. Activated AM phagocytosis and the secretion of various cytokines (e.g. tumor necrosis factor (TNF)), reactive oxygen species (ROS), and nitric oxide (NO) as part of the innate immune response $(71,75)$ in asthma.

Activated AECs and AMs release cytokines that stimulate resident airway dendritic cells (DCs), which are multifunctional immune cells that coordinate allergic responses in the lung. During exposure to foreign antigens, these antigen-presenting cells (APCs) activate T- and Bcells, thus connecting innate and adaptive immunity. The activation of T- and B-cells leads to antibody production by B lymphocytes (71) relevant to asthma pathogenesis.

AMs also block antigen presentation thereby modulating immune responses by inhibiting DCs, T-cell, and B-cell activity in healthy tissues (75). In allergic asthmatic patients, the phagocytic activity of AMs is significantly decreased compared to healthy subjects, while the 
antigen presentation activity of DCs is significantly increased. This highlights the importance of AMs in the coordination and control of allergic responses in asthma (75).

Through activation of immune responses in airways of asthmatic patients, the transcription factor GATA3 and the alarmin IL-33 help native T-cells differentiate into Type 2 cells (Th2). The Th2 phenotype induces type 2 immune responses in patients with asthma (74). During this inflammatory process, eosinophil influx into the airways causes persistent airway inflammation, airflow obstruction, and AHR. Eosinophils activate and damage airway tissues by secreting high concentrations of pro-inflammatory cytokines, chemokines, growth factors, and peptides from their secretory granules (63). Mast cells are another immune cell that produces inflammatory mediators including immunoglobulin E (IgE) and acute-phase mediators such as cysteinyl leukotrienes $(73,74)$. Production of $\operatorname{IgE}$ promotes histamine secretion, an acute inflammatory mediator, that contributes to the clinical manifestation of asthma, such as mucus metaplasia and bronchospasm (74).

\section{ER Stress and the Pathogenesis of Asthma}

Induction of ER stress and activation of the UPR in airway epithelial cells (AECs) adversely affects asthma. Stimuli important in the development of allergic asthma include aeroallergens, oxidative stress, bacteria, pollutants, and viral infections, all of which disrupt ER integrity and can act as inducers of ER $(71,74)$. The ER stress signaling network is controlled by three related transmembrane stress sensors of the UPR pathway located in the ER lumen. Acute and prolonged activations of UPR proteins can lead to the development of allergic airway inflammation (71, 76). Asthma-driven type 2 inflammation and expression of IFN-stimulated genes (ISGs) are both independently associated with elevated expression of ER stress genes (77). 
Preliminary investigation has highlighted the link between the differentiation of neutrophils and mitochondrial ATP production through activation of an arm of the UPR pathway (78). UPR also mediates neutrophil cell apoptosis via the activation of the CHOP-PERK arm (79). Several studies have also revealed that ER stress and UPR activation play a critical role in the pathogenesis of severe or steroid-resistant bronchial asthma by regulating NF- $\kappa \beta(80)$.

Approximately $85 \%$ of asthma exacerbations are caused by viral infections. During the Spring, Fall, and Winter seasons, viruses such as Rhinoviruses (RV), Influenza, and human respiratory syncytial virus (RSV), can increase acute symptoms of asthma. Although several viruses can provoke asthma symptoms, there is evidence that allergens can amplify the adverse effects of viruses on asthma symptom control. Most viruses appear to use the pro-survival antiapoptotic arms of the UPR to enhance replication by increasing ER capacity (81-83).

Airway goblet cells express IRE1 $\beta$, a key UPR sensor, which is responsible for inducing genes involved in mucus-secretion and cell differentiation, the mucins MUC5AC and MUC5B, and protein glycosylation $(71,84)$. During ovalbumin (OVA)-induced experimental asthma, IRE1 $\beta$ has a pivotal role in goblet cell metaplasia (GCM), a hallmark feature of asthma (71). During exposure to allergens, IRE1 $\beta$ modulates the level of ARG2 and MUC5AC; thus increasing the immune reactivity of IRE1 $\beta$ in the airway epithelium, which in turn induces expression of AGR2 $(71,84)$. Further, during allergic inflammation in Agr2-/- knockout mice, the production of mucins MUC5AC and MUC5B are reduced. And in Irel $\beta^{-}$and Agr $2^{-}$knockout mice, the airway epithelium displays a lack of the mucin layer (71).

The other ER transmembrane sensors, PERK, counteracts IRE1 $\beta$ activity by downregulating mucus overproduction. The transcription factor Nrf2 plays an important role in 
PERK-mediated cell survival. Nrf2 deficiency causes an increase in mucus cell hyperplasia and secretion of Th2 cytokines that results in allergen hypersensitivity $(71,76)$. The transcription factor 6 (ATF6), a component of ER stress, is induced by complex allergens such as HDM in airway epithelial cells $(64,65)$. Oasis is a member of the ATF6 family that participates in the differentiation of lung goblet cells, collagen production, and is involved in lung repair (84). In experimental asthma induced by OVA or HDM, higher activation of ATF6 $\alpha$ and XBP1 leads to mucus metaplasia and pro-inflammatory responses. Also, overexpression of CHOP due to the activation of ATF6 during ER stress induces apoptosis in type II alveolar epithelial cells and subsequent lung fibrosis (64). ATF6 downregulates Nogo-B protein that plays an important role in shaping the tubular structure of the ER. And the expression of Nogo-B in the airway epithelium of asthmatic subjects is reduced significantly.

Along with the induction of ATF6 $\alpha$ in response to HDM exposure, ER-resident protein 57 (ERp57) is upregulated in airway epithelial cells $(64,65)$. Hoffman et al. showed that ERp57 induces airway inflammation, AHR, and airway fibrosis in a mouse model of allergic asthma $(64,85)$. Subsequently, specific targeted deletion of ERp57 in lung epithelial cells attenuated the features of asthma in mice with allergic airways disease (86). Siddesha et al. showed that TUDCA (Tauroursodeoxycholic acid) acts as an ER-stress inhibitor chaperone. It extensively attenuates the expression of HDM (house dust mite)-induced ER-stress marker genes, including ATF-6, ERp57, XBP1s, CHOP, and GRP78, in lung lysates during preventive and therapeutic regimens (87). 
Role of Orosomucoid like 3 (ORMDL3) in Asthma and the UPR

Calcium ions play an important role in many cellular functions. Further, maintenance of calcium homeostasis within the ER is vital for signal transduction pathways, protein translation/processing/trafficking, and cell division $(71,88)$. Any disruption in luminal calcium levels within the ER induces ER stress and activates the UPR (70, 89).

Orosomucoid-like3 (ORMDL3) is a critical transmembrane protein anchored in the ER (63). ORMDL3 has been associated with asthma and a series of autoimmune disorders and is involved in ER-mediated inflammatory responses. However, the crucial molecular mechanism underlying its expression is not clearly understood (90-92). This protein is a conserved family of ER-resident proteins that regulates $\mathrm{Ca}^{2+}$ homeostasis through a membrane protein known as the sarco-endoplasmic reticulum calcium-ATPase pump (SERCA). SERCA controls the amount of calcium ions that enter the ER $(68,71)$. ORMDL3, also known as ORMDL sphingolipid biosynthesis regulator 3, physiologically downregulates the biosynthesis of sphingolipids which are key elements in cell communication, trafficking, and inflammation $(64,70,71)$. As mentioned previously, asthma is a complex disease with both genetic predisposition and environmental factors involved in its pathogenesis (67). Several genome-wide associated studies (GWASs) identified that the ORMDL3 gene as one of several important genes linked to the pathogenesis of asthma $(66,70,71,89)$. Based on genomic analyses, single nucleotide polymorphisms (SNPs) in the $17 \mathrm{q} 21$ region of the chromosome are associated with ORMDL3 $(66,70,71)$. This gene is a potential risk factor for both childhood and adult asthma, and it is induced with exposure to allergens, including tobacco smoke, OVA, interleukin-3 (IL-3), and interleukin-4 (IL-4) in airway epithelial cells (71, 93-96). 
The $\mathrm{T}$ allele of the ORMDL3 rs7216389 polymorphism carries an increased risk of developing asthma (97). This allele of the SNP at the 17q21 locus, rs7216389, is associated with significantly higher FeNO levels and peripheral eosinophil counts in adults (98). Higher levels of ORMDL3 expression in CD8 ${ }^{+}$T-cell, B-cell and eosinophils compared to monocytes (in a cellspecific pattern of ORMDL3 expression) may explain the connection between this gene and asthma pathogenesis. ORMDL3 expression may act on eosinophil inflammatory functions and its trafficking, or it may contribute to asthma severity via increasing allergen-specific IgE in Bcells $(91,92)$.

ORMDL3 expression is also implicated in the adhesion of microbes on the epithelial surface via its involvement in the protein transcription of ICAM1, the major receptor for the human rhinovirus and several inhaled bacterial pathogens (99). Conversely, increased expression of ORMDL 3 contributes to a boosted antiviral defense in times of amplified rhinoviral load (100). Knockdown of ORMDL3 in an asthmatic mouse model can reduce AHR, airway inflammation, and key markers of allergic inflammation such as concentrations of IL-4, IL-5 and IL-13 cytokines in BAL fluid. Alleviation of symptoms and airway remodeling appear to be the inactivation of the JNK1/2-MMP-9 pathway (101).

Of note, ORMDL3 expression correlates positively with the expression of SERCA2b (70), and the expression of ORMDL3 can activate ATF6 in the UPR pathway $(70,71,93)$. Thus, the activation of ATF6 increases the expression of SERCA2b, which leads to ASM cell proliferation and airway remodeling in asthma. And insufficient expression of SERCA can also induce airway remodeling (68). Patients with asthma can overexpress ORMDL3 particularly in response to human rhinovirus (HRV) and in murine models during OVA challenge (63). Higher levels of ORMDL3 inhibits the expression of SERCA that results in perturbation of $\mathrm{Ca}^{2+}$ 
homeostasis in the ER. ORMDL3 can then act as an endogenous inducer of the UPR (67). Consequently, dysregulation of ORMDL3 in airway epithelial cells leads to progression of ER stress, which increases the activation of the UPR pathway. These factors all together induce various inflammatory pathways that link together ORMDL3, UPR, and asthma in a complex web of responses $(71,80)$.

\section{UPR Triggers in Asthma}

Environmental triggers for allergic asthma can act as UPR activators in the airways. Common triggers include HDM, pollens, molds, animal dander, cockroach, fungal spores, chemical irritants, cigarette smoke, diesel particles, ozone gas, and viral or bacterial infections $(71,74)$. Emotional or psychological conditions such as anger, fear, stress and physical exercise can trigger inflammatory responses of asthma (74). All these factors can lead to dysregulation of innate immune function and ER homeostasis $(71,74,80)$. A summary of the link between UPR and asthma pathogenesis is illustrated in Figure 2.

Emerging literature suggests that UPR is involved in both innate and adaptive immune responses (102). The adaptive arm of the UPR restores protein folding in the ER while UPR signaling is essential in many immune cell functions such as differentiation of B cells to plasma cells, immunoglobulin production (103), antigen presentation $(104,105)$, cell development, and survival of both conventional and plasmacytoid dendritic cells $(106,107)$, immune cell phenotype (108). Further to this, XBP1 splicing is important during the early stages of both B and $\mathrm{T}$ cell development while it is enhanced in antigen specific $\mathrm{CD}^{+} \mathrm{T}$ cells during viral and bacterial infection (109). In summary, ER stress triggered UPR activation is a requirement for 
key components of the immune system and impairment of UPR may result in various immune disorders including asthma.

\section{SUMMARY and FUTURE DIRECTIONS}

Recent evidence indicates that ER stress can be triggered by several common pathogens affecting the lungs. In recent years the effects of ER stress and activated UPR have attracted broad research interest both as a cause and consequence of airway diseases such as asthma (110112). Continuous exposure of pulmonary cells to diverse environmental stimulants can activate UPR pathways specifically in the lung. IRE1 $\beta$ expressed by Goblet cells has an essential role in the production of MUC5B and MUC5AC mucins. This expression is associated with increased mucin secretion in these disorders. On the other hand, ATF6 increases the expression of ER $\mathrm{Ca}^{2+}$ pump (SERCA2), interfering with the proliferation of the ASM in asthma. ATF6 is upregulated in airway epithelial cells with Th2 cytokines $(113,114)$. OASIS is the other transcription factor that is expressed in high levels in the lung, affecting the production of collagen, lung repair, and differentiation of secretory cells. Recent investigations indicate that IRE1 plays an important role in the regulation of the secretome (115) which can also subsequently affect organisms' microenvironment. Thus, the activation of IRE1 can be a key component of disease immuneregulation relevant to asthma pathogenesis. Therefore, it will be very important to address IRE1 activation in infiltrated immune cells, lung epithelial cells, and lung mesenchymal cells to gain a better understanding of disease mechanisms. This will allow for the future development of targeted therapeutics in asthma.

Disruptions of ER stress/UPR also manifest in several other pulmonary disorders. As reported, there is increased expression of IRE $1 \beta$ in respiratory epithelial cells not only in asthma 
but also in cystic fibrosis and chronic obstructive pulmonary disease (COPD). In COPD, there is an increase in the expression of UPR transcription factors, such as p-eIF2 $\alpha, \mathrm{CHOP}$, and several proteins involved in ERAD pathway. Although two arms of ATF6 and IRE1 are not affected, the expression of these UPR transcription factors positively correlates with the degree and severity of airflow obstruction in lung diseases (116-118). In patients with idiopathic pulmonary fibrosis (IPF), there is enhanced expression of GRP78, XBP1, IRE1, ATF6, CHOP in type II alveolar epithelial cells as well as induction of ATF4, CHOP, and BAX (119-121).

Cigarette smoke (CS) affects the lung in many diverse ways and contributes to the development of asthma, COPD, IPF, and bronchiectasis, to name a few. CS alters protein metabolism and the UPR cascade via oxidative stress, which damages a variety of lung proteins irreversibly. Acute exposure to cigarette smoke causes an increase in the expression of GRP78, Calnexin, Calreticulin, ATF4, PERK, p-e IF2 $\alpha$, and CHOP. However, persistent consumption of CS just increases the expression of GRP78, Calnexin, Calreticulin in human lung cells. In general, smoking not only increases the loading of proteins in ER, but also degrades the ability of ER capacity $(122,123)$. Overall, while several in vivo and in vitro studies have shown the profibrotic effect of ER stress, our understanding of the exact role of UPR in the pathogenesis of lung diseases remains limited with many gaps in our knowledge.

Many investigators are working to find ways to target ER stress and components of the UPR to help treat lung diseases and their complications. For instance, the chemical chaperones 4-phenyl butyric acid (4-PBA) and taurohyodeoxycholic acid (TUDCA) have beneficial effects in a mouse model of fibrosis $(117,122,124)$. Recent work from Nakada et al. explores how therapies based on conjugated bile acids can attenuate allergen-induced allergic airway disease in mice while also inhibiting UPR via targeting binding of ATF6 $\alpha$ (125). Given the biological 
complexity of signalling pathways in cells, identifying a specific diagnostic biomarker could help advance novel therapies in lung diseases affected by ER stress/UPR.

A greater understanding of these cell fate processes may lead to deeper insights into cellular dysfunction that manifests as disease pathophysiology. Since the discovery of UPR, great advances in cell biology have been made, but we are just beginning to apply this knowledge to human disease. The uniqueness of cell fate mechanisms is that these are cellular programs that commit the cell to an outcome and have directionality. Therefore, they provide a unique avenue to modulate such processes via pharmacological (and potentially other nonpharmacological) interventions. In recent investigations, for example, the role of the UPR in regulating the secretome of cells has been widely investigated in cancer (115). Such new knowledge could inform the field of lung diseases in important ways, and in the case of asthma, lead to novel ways of targeting inflammatory responses that hinge on the modulation of ER stress/UPR. 


\section{REFERENCES}

1. Iranpour M, Moghadam AR, Yazdi M, Ande SR, Alizadeh J, Wiechec E, Lindsay R, Drebot M, Coombs KM, Ghavami S. Apoptosis, autophagy and unfolded protein response pathways in Arbovirus replication and pathogenesis. Expert Rev Mol Med 2016; 18: e1.

2. Duvigneau JC, Luis A, Gorman AM, Samali A, Kaltenecker D, Moriggl R, Kozlov AV. Crosstalk between inflammatory mediators and endoplasmic reticulum stress in liver diseases. Cytokine 2018.

3. Mehrbod P, Ande SR, Alizadeh J, Rahimizadeh S, Shariati A, Malek H, Hashemi M, Glover KKM, Sher AA, Coombs KM, Ghavami S. The roles of apoptosis, autophagy and unfolded protein response in arbovirus, influenza virus, and HIV infections. Virulence 2019; 10: 376-413.

4. Ozgur R, Uzilday B, Iwata Y, Koizumi N, Turkan I. Interplay between unfolded protein response and reactive oxygen species: a dynamic duo. Journal of experimental botany 2018: ery040.

5. Manalo RVM, Medina PMB. The endoplasmic reticulum stress response in disease pathogenesis and pathophysiology. Egyptian Journal of Medical Human Genetics 2017.

6. Schröder M, Kaufman RJ. ER stress and the unfolded protein response. Mutation Research/Fundamental and Molecular Mechanisms of Mutagenesis 2005; 569: 29-63.

7. Kapoor A, Sanyal AJ. Endoplasmic reticulum stress and the unfolded protein response. Clinics in liver disease 2009; 13: 581-590. 
8. Salminen A, Kaarniranta K. ER stress and hormetic regulation of the aging process. Ageing research reviews 2010; 9: 211-217.

9. Hombach-Klonisch S, Mehrpour M, Shojaei S, Harlos C, Pitz M, Hamai A, Siemianowicz K, Likus W, Wiechec E, Toyota BD, Hoshyar R, Seyfoori A, Sepehri Z, Ande SR, Khadem F, Akbari M, Gorman AM, Samali A, Klonisch T, Ghavami S. Glioblastoma and chemoresistance to alkylating agents: Involvement of apoptosis, autophagy, and unfolded protein response. Pharmacol Ther 2018; 184: 13-41.

10. Kim I, Xu W, Reed JC. Cell death and endoplasmic reticulum stress: disease relevance and therapeutic opportunities. Nature reviews Drug discovery 2008; 7: 1013.

11. Hampton RY. ER stress response: getting the UPR hand on misfolded proteins. Current Biology 2000; 10: R518-R521.

12. Ghavami S, Yeganeh B, Zeki AA, Shojaei S, Kenyon NJ, Ott S, Samali A, Patterson J, Alizadeh J, Moghadam AR, Dixon IMC, Unruh H, Knight DA, Post M, Klonisch T, Halayko AJ. Autophagy and the unfolded protein response promote profibrotic effects of TGF-beta1 in human lung fibroblasts. Am J Physiol Lung Cell Mol Physiol 2018; 314 : L493-L504.

13. Mori K. Signalling pathways in the unfolded protein response: development from yeast to mammals. J Biochem 2009; 146: 743-750.

14. Ghavami S, Yeganeh B, Stelmack GL, Kashani HH, Sharma P, Cunnington R, Rattan S, Bathe K, Klonisch T, Dixon IM, Freed DH, Halayko AJ. Apoptosis, autophagy and ER 
stress in mevalonate cascade inhibition-induced cell death of human atrial fibroblasts. Cell Death Dis 2012; 3: e330.

15. Mokarram P, Albokashy M, Zarghooni M, Moosavi MA, Sepehri Z, Chen QM, Hudecki A, Sargazi A, Alizadeh J, Moghadam AR, Hashemi M, Movassagh H, Klonisch T, Owji AA, Los MJ, Ghavami S. New frontiers in the treatment of colorectal cancer: Autophagy and the unfolded protein response as promising targets. Autophagy 2017; 13: 781-819.

16. Rao RV, Ellerby H, Bredesen DE. Coupling endoplasmic reticulum stress to the cell death program. Cell death and differentiation 2004; 11: 372.

17. Corazzari M, Gagliardi M, Fimia GM, Piacentini M. Endoplasmic reticulum stress, unfolded protein response, and cancer cell fate. Frontiers in oncology 2017; 7: 78.

18. Hetz C. The unfolded protein response: controlling cell fate decisions under ER stress and beyond. Nature reviews Molecular cell biology 2012; 13: 89.

19. Sano R, Reed JC. ER stress-induced cell death mechanisms. Biochimica et Biophysica Acta (BBA)-Molecular Cell Research 2013; 1833: 3460-3470.

20. Schmidt RM, Schessner JP, Borner GH, Schuck S. The proteasome biogenesis regulator Rpn4 cooperates with the unfolded protein response to promote ER stress resistance. eLife 2019; 8: e43244.

21. Regulation H. The Unfolded Protein Response: From Stress Pathway to. science 2011; 1209038: 334. 
22. Gorman AM, Healy SJ, Jäger R, Samali A. Stress management at the ER: regulators of ER stress-induced apoptosis. Pharmacology \& therapeutics 2012; 134: 306-316.

23. Ron D, Walter P. Signal integration in the endoplasmic reticulum unfolded protein response. Nature reviews Molecular cell biology 2007; 8: 519.

24. Lin JH, Li H, Yasumura D, Cohen HR, Zhang C, Panning B, Shokat KM, LaVail MM, Walter P. IRE1 signaling affects cell fate during the unfolded protein response. science 2007; 318: 944-949.

25. Yoshida H. ER stress and diseases. The FEBS journal 2007; 274: 630-658.

26. Hetz C, Chevet E, Oakes SA. Proteostasis control by the unfolded protein response. Nature cell biology 2015; 17: 829.

27. Doultsinos D, Avril T, Lhomond S, Dejeans N, Guédat P, Chevet E. Control of the unfolded protein response in health and disease. SLAS DISCOVERY: Advancing Life Sciences $R \& D$ 2017; 22: 787-800.

28. Lai E, Teodoro T, Volchuk A. Endoplasmic reticulum stress: signaling the unfolded protein response. Physiology 2007; 22: 193-201.

29. Walter P, Ron D. The unfolded protein response: from stress pathway to homeostatic regulation. science 2011; 334: 1081-1086.

30. Brookes SJ, Barron MJ, Dixon MJ, Kirkham J. The Unfolded Protein Response in Amelogenesis and Enamel Pathologies. Frontiers in physiology 2017; 8: 653. 
31. Brewer JW, Hendershot LM. Building an antibody factory: a job for the unfolded protein response. Nature immunology 2005; 6: 23.

32. Lindholm D, Korhonen L, Eriksson O, Kõks S. Recent insights into the role of unfolded protein response in ER stress in health and disease. Frontiers in cell and developmental biology 2017; 5: 48 .

33. Zhao L, Ackerman SL. Endoplasmic reticulum stress in health and disease. Current opinion in cell biology 2006; 18: 444-452.

34. Chevet E, Hetz C, Samali A. Endoplasmic reticulum stress-activated cell reprogramming in oncogenesis. Cancer discovery 2015; 5: 586-597.

35. Todd DJ, Lee A-H, Glimcher LH. The endoplasmic reticulum stress response in immunity and autoimmunity. Nature reviews immunology 2008; 8: 663.

36. Plate L, Wiseman RL. Regulating Secretory Proteostasis through the Unfolded Protein Response: From Function to Therapy. Trends Cell Biol 2017; 27: 722-737.

37. Senft D, Ze'ev AR. UPR, autophagy, and mitochondria crosstalk underlies the ER stress response. Trends in biochemical sciences 2015; 40: 141-148.

38. Shpilka T, Haynes CM. The mitochondrial UPR: mechanisms, physiological functions and implications in ageing. Nature reviews Molecular cell biology 2018; 19: 109.

39. Schulz AM, Haynes CM. UPRmt-mediated cytoprotection and organismal aging. Biochimica et Biophysica Acta-Bioenergetics 2015; 1847: 1448-1456. 
40. Schröder M, Kaufman R. The mammalian unfolded protein response. Annu Rev Biochem 2005; 74: 739-789.

41. Naresh NU, Haynes CM. Signaling and Regulation of the Mitochondrial Unfolded Protein Response. Cold Spring Harb Perspect Biol 2019; 11: a033944.

42. Cybulsky AV. Endoplasmic reticulum stress, the unfolded protein response and autophagy in kidney diseases. Nature Reviews Nephrology 2017; 13: 681.

43. Aksoy M, Shetty N, Ji R, Shariff N, Binnat N, Cordova K, Kelsen S. The Endoplasmic Reticulum Chaperone, GRP78, Protects Against the Adverse Effects of Cigarette Smoke on Lung Cell Proteostasis. D27 REDOX AND BEYOND: MITOCHONDRIA, ER STRESS, AND PROTEASOMES: American Thoracic Society; 2018. p. A6368-A6368.

44. Thamsen M, Ghosh R, Auyeung VC, Brumwell A, Chapman HA, Backes BJ, Perara G, Maly DJ, Sheppard D, Papa FR. Small molecule inhibition of IRE1 $\alpha$ kinase/RNase has antifibrotic effects in the lung. PloS one 2019; 14: e0209824.

45. Wang M, Wey S, Zhang Y, Ye R, Lee AS. Role of the unfolded protein response regulator GRP78/BiP in development, cancer, and neurological disorders. Antioxidants \& redox signaling 2009; 11: 2307-2316.

46. Casas C. GRP78 at the centre of the stage in cancer and neuroprotection. Frontiers in neuroscience 2017; 11: 177.

47. Naidoo N. ER and aging_-protein folding and the ER stress response. Ageing research reviews 2009; 8: 150-159. 
48. Gopal U, Pizzo SV. The Endoplasmic Reticulum Chaperone GRP78 Also Functions as a Cell Surface Signaling Receptor. Cell Surface GRP78, a New Paradigm in Signal Transduction Biology: Elsevier; 2018. p. 9-40.

49. Lin JH, Li H, Zhang Y, Ron D, Walter P. Divergent effects of PERK and IRE1 signaling on cell viability. PloS one 2009; 4: e4170.

50. Chen Y, Brandizzi F. IRE1: ER stress sensor and cell fate executor. Trends in cell biology $2013 ; 23: 547-555$.

51. Tsuru A, Fujimoto N, Takahashi S, Saito M, Nakamura D, Iwano M, Iwawaki T, Kadokura H, Ron D, Kohno K. Negative feedback by IRE1 $\beta$ optimizes mucin production in goblet cells. Proc Natl Acad Sci US A 2013; 110: 2864-2869.

52. Rahmati M, Amanpour S, Kharman-Biz A, Moosavi MA. Endoplasmic Reticulum Stress as a Therapeutic Target in Cancer: A mini review. Basic \& Clinical Cancer Research 2017; 9: $38-48$.

53. Bashir S, Fazili KM. Bid as a novel interacting partner of IRE1 differentially regulating its RNAse activity. bioRxiv 2019: 572222.

54. Groenendyk J, Peng Z, Dudek E, Fan X, Mizianty MJ, Dufey E, Urra H, Sepulveda D, RojasRivera D, Lim Y. Interplay between the oxidoreductase PDIA6 and microRNA-322 controls the response to disrupted endoplasmic reticulum calcium homeostasis. Sci Signal 2014; 7: ra54-ra54. 
55. Mathew A. The P5 disulfide switch: taming the aging unfolded protein response. Cell Stress Chaperones 2015; 20: 743-751.

56. Eletto D, Eletto D, Dersh D, Gidalevitz T, Argon Y. Protein disulfide isomerase A6 controls the decay of IRE1 $\alpha$ signaling via disulfide-dependent association. Molecular cell 2014; 53: $562-576$.

57. Raven JF, Baltzis D, Wang S, Mounir Z, Papadakis AI, Gao HQ, Koromilas AE. PKR and PKR-like endoplasmic reticulum kinase induce the proteasome-dependent degradation of cyclin D1 via a mechanism requiring eukaryotic initiation factor $2 \alpha$ phosphorylation. Journal of Biological Chemistry 2008; 283: 3097-3108.

58. Zhao L., Ackerman S. Endoplasmic reticulum stress in health and disease. Curr Opin Cell Biol 2006; 18: 444-452.

59. Nadanaka S, Okada T, Yoshida H, Mori K. Role of disulfide bridges formed in the luminal domain of ATF6 in sensing endoplasmic reticulum stress. Molecular and cellular biology 2007; 27: 1027-1043.

60. Oka OB, van Lith M, Rudolf J, Tungkum W, Pringle MA, Bulleid NJ. ERp18 regulates activation of ATF6 $\alpha$ during unfolded protein response. EMBO J 2019.

61. Karagöz GE, Aragón T, Acosta-Alvear D. Recent advances in signal integration mechanisms in the unfolded protein response. F1000Res 2019; 8. 
62. Qiong-Qiong Xinga YL, Jian-Ya Xua, Dou Dinga, Xia Zhaoa. Astragalus polysaccharide modulates ER stress response in an OVA-LPS induced murine model of severe asthma. International Journal of Biological Macromolecules 2016; 93: 995-1006.

63. Yuan Lu J-YX, Xiao-Hua Zhang, Xia Zhao. Gu-Ben-Fang-Xiao decoction attenuates sustained airway inflammation by suppressing ER stress response in a murine asthma remission model of respiratory syncytial virus infection. Journal of Ethnopharmacology 2016; 192: 496-509.

64. Sidra M. Hoffman DGC, Karolyn G. Lahue, Jonathon M. Cahoon, Gurkiranjit K. Rattu, Nirav Daphtary, Minara Aliyeva, Karen A. Fortner, Serpil C. Erzurum, Suzy A.A. Comhair, Prescott G. Woodruff. Protein Disulfide Isomerase-ERp57 regulates allergeninduced airways inflammation, fibrosis and hyperresponsiveness. J Allergy Clin Immunol 2016; 137: 822-832.

65. Jalahalli M. Siddesha EMN, Bethany R. Mihavics, Sidra M. Hoffman, Gurkiranjit K. Rattu, Nicolas Chamberlain, Jonathon M. Cahoon, Karolyn G. Lahue, Nirav Daphtary, Minara Aliyeva, David G. Chapman, Dhimant H. Desai. Effect of a chemical chaperone, tauroursodeoxycholic acid, on HDM-induced allergic airway disease. Am J Physiol Lung Cell Mol Physiol 2016; 310: L1243-L1259.

66. Clement Oyeniran JLS, Nitai C. Hait, Wei-Ching Huang, Dorit Avni, Michael Maceyka, Jason Newton, Jeremy C. Allegood, Alison Montpetit, Daniel H. Conrad, Sheldon Milstien, and Sarah Spiegel. Aberrant ORM (yeast)-like protein isoform 3 (ORMDL3) expression dysregulates ceramide homeostasis in cells and ceramide exacerbates allergic asthma in mice. J ALLERGY CLIN IMMUNOL 2015; 136: 18. 
67. Yun-Feng Zhao Y-ML, Wei Xiong, Xue-Ling Wu. Genetic variation in ORMDL3 gene may contribute to the risk of asthma: A meta-analysis. Human immunology 2014; 75: 960967.

68. James Wei SR, Ehab A. Ayaub, Jeffrey G. Dickhout, Kjetil Ask. Protein Misfolding and Endoplasmic Reticulum Stress in Chronic Lung Disease Translating Basic Research into Clinical Practice 2013; 143: 1098-1105.

69. Carr TF, Zeki AA, Kraft M. Eosinophilic and Noneosinophilic Asthma. Am J Respir Crit Care Med 2018; 197: 22-37.

70. Stephan Loser LGG, Youming Zhang, Katrein Schaefer, Simone A. Walker, James Buckley, Laura Denney, Charlotte H. Dean, William O. C. Cookson, Miriam F. Moffatt, and Clare M. Lloyd. Pulmonary ORMDL3 is critical for induction of Alternaria-induced allergic airways disease. J ALLERGY CLIN IMMUNOL 2016; 139: 15.

71. Janssens FOBLS. The UPR and lung disease. Seminars in Immunopathology 2013.

72. Sara C. Sebaga OMK, John D. Paschkea, Christopher J. Wintersa, Alejandro P. Comellasa, Isabella M. Grumbach. Inhibition of the mitochondrial calcium uniporter prevents IL-13 and allergen-mediated airway epithelial apoptosis and loss of barrier function Experimental Cell Research 2018; 362: 400-411.

73. Robert F. Lemanske WWB. Asthma: clinical expression and molecular mechanisms. $J$ ALLERGY CLIN IMMUNOL 2010: 8. 
74. Pathinayake PS HA-Y, Waters DW, Hansbro PM, Wood LG and Wark PAB Understanding the Unfolded Protein Response in the Pathogenesis of Asthma. Front Immunol 2018; 9.

75. Anne-Marie Madore SP, VÊronique Turmel, Michel Laviolette, E'lyse Y. Bissonnette, Catherine Laprise Alveolar macrophages in allergic asthma: An expression signature characterized by heat shock protein pathways. Human Immunology 2010; 71: 144-150.

76. Cullinan SB ZD, Hannink M, Arvisais E, Kaufman RJ, Diehl JA. Nrf2 is a direct PERK substrate and effector of PERK-dependent cell survival. Mol Cell Biol 2003; 23: 71987209.

77. Bhakta NR, Christenson SA, Nerella S, Solberg OD, Nguyen CP, Choy DF, Jung KL, Garudadri S, Bonser LR, Pollack JL, Zlock LT, Erle DJ, Langelier C, Derisi JL, Arron JR, Fahy JV, Woodruff PG. IFN-stimulated Gene Expression, Type 2 Inflammation, and Endoplasmic Reticulum Stress in Asthma. Am J Respir Crit Care Med 2018; 197: 313324.

78. Tanimura A, Miyoshi K, Horiguchi T, Hagita H, Fujisawa K, Noma T. Mitochondrial Activity and Unfolded Protein Response are Required for Neutrophil Differentiation. Cell Physiol Biochem 2018; 47: 1936-1950.

79. Grechowa I, Horke S, Wallrath A, Vahl CF, Dorweiler B. Human neutrophil elastase induces endothelial cell apoptosis by activating the PERK-CHOP branch of the unfolded protein response. FASEB J 2017; 31: 3868-3881.

80. So Ri Kim YCL. Endoplasmic Reticulum Stress and the Related Signaling Networks in Severe Asthma Allergy Asthma Immunol Res 2015; 7: 106-117. 
81. Yeganeh B, Moghadam AR, Tran AT, Rahim MN, Ande SR, Hashemi M, Coombs KM, Ghavami S. Asthma and influenza virus infection: focusing on cell death and stress pathways in influenza virus replication. Iranian Journal of Allergy, Asthma Immunology 2013: 1-17.

82. Roberson EC, Tully JE, Guala AS, Reiss JN, Godburn KE, Pociask DA, Alcorn JF, Riches DW, Dienz O, Janssen-Heininger YM. Influenza Induces Endoplasmic Reticulum Stress, Caspase-12-Dependent Apoptosis, and c-Jun N-Terminal Kinase-Mediated Transforming Growth Factor- $\beta$ Release in Lung Epithelial Cells. Am J Respir Cell Mol Biol 2012; 46: 573-581.

83. Errico M, Andrea B, D'auria D, Gennaro M. Respiratory infections and asthma. Allergy $2000 ; 55: 42-45$.

84. Kelsen SG. The Unfolded Protein Response in Chronic Obstructive Pulmonary Disease AnnalsATS 2016; 13: 8 .

85. Hoffman SM, Tully JE, Nolin JD, Lahue KG, Goldman DH, Daphtary N, Aliyeva M, Irvin CG, Dixon AE, Poynter ME, Anathy V. Endoplasmic reticulum stress mediates house dust mite-induced airway epithelial apoptosis and fibrosis. Respir Res 2013; 14: 141.

86. Hoffman SM, Chapman DG, Lahue KG, Cahoon JM, Rattu GK, Daphtary N, Aliyeva M, Fortner KA, Erzurum SC, Comhair SA, Woodruff PG, Bhakta N, Dixon AE, Irvin CG, Janssen-Heininger YM, Poynter ME, Anathy V. Protein disulfide isomerase-endoplasmic reticulum resident protein 57 regulates allergen-induced airways inflammation, fibrosis, and hyperresponsiveness. J Allergy Clin Immunol 2016; 137: 822-832 e827. 
87. Siddesha JM, Nakada EM, Mihavics BR, Hoffman SM, Rattu GK, Chamberlain N, Cahoon JM, Lahue KG, Daphtary N, Aliyeva M. Effect of a chemical chaperone, tauroursodeoxycholic acid, on HDM-induced allergic airway disease. American Journal of Physiology-Lung Cellular Molecular Physiology 2016; 310: L1243-L1259.

88. Huiling He ML, Thomas S, Mccromick, Clark W. Distelhorst. Maintenance of Calcium Homeostasis in the Endoplasmic Reticulum by Bcl-2. J Cell Biol 1997; 138: 1219-1228.

89. Gerard Cantero-Recasens CsF, Fanny Rubio-Moscardo, Miguel A. Valverde, Rube 'n Vicente. The asthma-associated ORMDL3 gene product regulates endoplasmic reticulum-mediated calcium signaling and cellular stress. Human Molecular Genetics 2010; 19: 111-121.

90. Carreras-Sureda A, Cantero-Recasens G, Rubio-Moscardo F, Kiefer K, Peinelt C, Niemeyer BA, Valverde MA, Vicente R. ORMDL3 modulates store-operated calcium entry and lymphocyte activation. Human molecular genetics 2012; 22: 519-530.

91. Ha SG, Ge XN, Bahaie NS, Kang BN, Rao A, Rao SP, Sriramarao P. ORMDL3 promotes eosinophil trafficking and activation via regulation of integrins and CD48. Nature communications 2013; 4: 2479.

92. Kiefer K, Casas J, García-López R, Vicente R. Ceramide Imbalance and Impaired TLR4Mediated Autophagy in BMDM of an ORMDL3-Overexpressing Mouse Model. Int J Mol Sci 2019; 20: 1391.

93. Cao SS. Endoplasmic Reticulum Stress and Unfolded Protein Response in Inflammatory Bowel Disease. Inflamm Bowel Dis 2015; 21: 636-644. 
94. Li Y, Cao L, Yu Q, Xue H, Lu Y. Association between peripheral blood mononuclear cell ORMDL3 expression and the asthma predictive index in preschool children. $J$ Int Med Res 2019; 47: 3727-3736.

95. Kang MJ, Yu HS, Seo JH, Kim HY, Jung YH, Kim YJ, Kim HJ, Lee SY, Hong SJ.

GSDMB/ORMDL3 variants contribute to asthma susceptibility and eosinophil-mediated bronchial hyperresponsiveness. Hum Immunol 2012; 73: 954-959.

96. Toncheva AA, Potaczek DP, Schedel M, Gersting SW, Michel S, Krajnov N, Gaertner VD, Klingbeil JM, Illig T, Franke A, Winkler C, Hohlfeld JM, Vogelberg C, von Berg A, Bufe A, Heinzmann A, Laub O, Rietschel E, Simma B, Genuneit J, Muntau AC, Kabesch M. Childhood asthma is associated with mutations and gene expression differences of ORMDL genes that can interact. Allergy 2015; 70: 1288-1299.

97. Zhai WH, Song CY, Huang ZG, Sha H. Correlation between the genetic polymorphism of ORMDL3 gene and asthma risk: a meta-analysis. Genet Mol Res 2015; 14: 7101-7112.

98. Schwantes EA, Evans MD, Cuskey A, Burford A, Smith JA, Lemanske RF, Jr., Jarjour NN, Mathur SK. Elevated fractional exhaled nitric oxide and blood eosinophil counts are associated with a 17q21 asthma risk allele in adult subjects. J Asthma Allergy 2018; 11: $1-9$.

99. Zhang Y, Willis-Owen SAG, Spiegel S, Lloyd CM, Moffatt MF, Cookson W. The ORMDL3 Asthma Gene Regulates ICAM1 and Has Multiple Effects on Cellular Inflammation. Am J Respir Crit Care Med 2019; 199: 478-488. 
100. Song DJ, Miller M, Beppu A, Rosenthal P, Das S, Karta M, Vuong C, Mehta AK, Croft M, Broide DH. Rhinovirus Infection of ORMDL3 Transgenic Mice Is Associated with Reduced Rhinovirus Viral Load and Airway Inflammation. J Immunol 2017; 199: 22152224.

101. Wang H, Liu Y, Shi J, Cheng Z. ORMDL3 knockdown in the lungs alleviates airway inflammation and airway remodeling in asthmatic mice via JNK1/2-MMP-9 pathway. Biochem Biophys Res Commun 2019; 516: 739-746.

102. Janssens S, Pulendran B, Lambrecht BN. Emerging functions of the unfolded protein response in immunity. Nat Immunol 2014; 15: 910-919.

103. Reimold AM, Iwakoshi NN, Manis J, Vallabhajosyula P, Szomolanyi-Tsuda E, Gravallese EM, Friend D, Grusby MJ, Alt F, Glimcher LH. Plasma cell differentiation requires the transcription factor XBP-1. Nature 2001; 412: 300-307.

104. Liou HC, Boothby MR, Finn PW, Davidon R, Nabavi N, Zeleznik-Le NJ, Ting JP, Glimcher LH. A new member of the leucine zipper class of proteins that binds to the HLA DR alpha promoter. Science 1990; 247: 1581-1584.

105. Ravindran R, Khan N, Nakaya HI, Li S, Loebbermann J, Maddur MS, Park Y, Jones DP, Chappert P, Davoust J, Weiss DS, Virgin HW, Ron D, Pulendran B. Vaccine activation of the nutrient sensor GCN2 in dendritic cells enhances antigen presentation. Science 2014; 343: 313-317.

106. Osorio F, Tavernier SJ, Hoffmann E, Saeys Y, Martens L, Vetters J, Delrue I, De Rycke R, Parthoens E, Pouliot P, Iwawaki T, Janssens S, Lambrecht BN. The unfolded-protein- 
response sensor IRE-1alpha regulates the function of CD8alpha+ dendritic cells. $N a t$ Immunol 2014; 15: 248-257.

107. Iwakoshi NN, Pypaert M, Glimcher LH. The transcription factor XBP-1 is essential for the development and survival of dendritic cells. J Exp Med 2007; 204: 2267-2275.

108. Osorio F, Lambrecht B, Janssens S. The UPR and lung disease. Semin Immunopathol 2013; 35: 293-306.

109. Kamimura D, Bevan MJ. Endoplasmic reticulum stress regulator XBP-1 contributes to effector CD8+ T cell differentiation during acute infection. J Immunol 2008; 181: 54335441.

110. Marciniak SJ, Ron D. Endoplasmic reticulum stress signaling in disease. Physiological reviews 2006; 86: 1133-1149.

111. Kim H-K, Lee G-H, Bhattarai KR, Junjappa RP, Lee H-Y, Handigund M, Marahatta A, Bhandary B, Baek I-H, Pyo JS. PI3K $\delta$ contributes to ER stress-associated asthma through ER-redox disturbances: the involvement of the RIDD-RIG-I-NF- $\kappa$ B axis. Exp Mol Med 2018; 50: e444.

112. Jeong JS, Kim SR, Lee YC. Can Controlling Endoplasmic Reticulum Dysfunction Treat Allergic Inflammation in Severe Asthma With Fungal Sensitization? Allergy Asthma Immunol Res 2018; 10: 106-120.

113. Jeong JS, Kim SR, Cho SH, Lee YC. Endoplasmic Reticulum Stress and Allergic Diseases. Current allergy and asthma reports 2017; 17: 82. 
114. Kim SR, Lee YC. Endoplasmic reticulum stress and the related signaling networks in severe asthma. Allergy, asthma \& immunology research 2015; 7: 106-117.

115. Logue SE, McGrath EP, Cleary P, Greene S, Mnich K, Almanza A, Chevet E, Dwyer RM, Oommen A, Legembre P, Godey F, Madden EC, Leuzzi B, Obacz J, Zeng Q, Patterson JB, Jager R, Gorman AM, Samali A. Inhibition of IRE1 RNase activity modulates the tumor cell secretome and enhances response to chemotherapy. Nat Commun 2018; 9: 3267.

116. Marcinak SJ, Ron D. The unfolded protein response in lung disease. Proceedings of the American Thoracic Society 2010; 7: 356-362.

117. Osorio F, Lambrecht B, Janssens S. The UPR and lung disease. ‘: Springer; 2013. p. 293306.

118. Kelsen SG. The unfolded protein response in chronic obstructive pulmonary disease. Annals of the American Thoracic Society 2016; 13: S138-S145.

119. Parfrey H, Moseley E, Beardsley B, Knight J, Marciniak S, Rassl D. S74 Endoplasmic stress is associated with fibrosis in interstitial lung disease. BMJ Publishing Group Ltd; 2017.

120. Burman A, Tanjore H, Blackwell TS. Endoplasmic reticulum stress in pulmonary fibrosis. Matrix Biology 2018.

121. Wolters PJ, Collard HR, Jones KD. Pathogenesis of idiopathic pulmonary fibrosis. Annual Review of Pathology: Mechanisms of Disease 2014; 9: 157-179. 
122. Dickens JA, Malzer E, Chambers JE, Marciniak SJ. Pulmonary endoplasmic reticulum stress: Scars, Smoke and Suffocation. The FEBS journal 2018.

123. Mahmood SH. ROLE OF THE IRE/XBP-1 PATHWAY IN CIGARETTE SMOKE AFFECTED MACROPHAGE POLARIZATION IN VITRO.

124. Lenna S, Trojanowska M. The role of endoplasmic reticulum stress and the unfolded protein response in fibrosis. Current opinion in rheumatology 2012; 24.

125. Nakada EM, Bhakta NR, Korwin-Mihavics BR, Kumar A, Chamberlain N, Bruno SR, Chapman DG, Hoffman SM, Daphtary N, Aliyeva M, Irvin CG, Dixon AE, Woodruff PG, Amin S, Poynter ME, Desai DH, Anathy V. Conjugated bile acids attenuate allergeninduced airway inflammation and hyperresponsiveness by inhibiting UPR transducers. JCI Insight 2019; 4. 


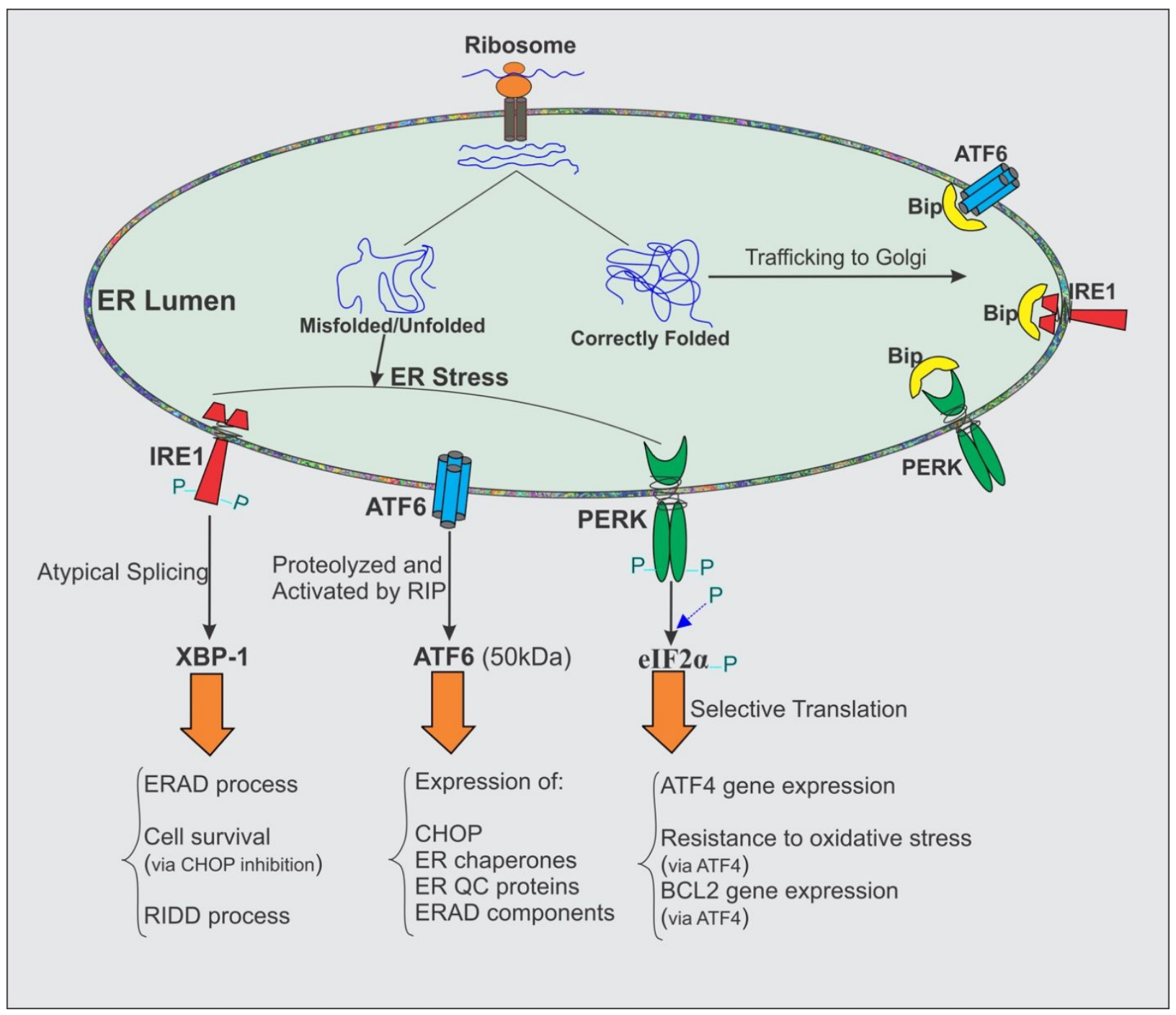

Figure 1. UPR Signaling Pathways. Proteins that are correctly folded in the endoplasmic reticulum (ER) are transferred to the Golgi for further modifications. Conversely, proteins that misfolded following synthesis promote ER stress and activate three independent pathways (three different UPR arms) driven by ATF6, PERK, and IRE1. This counteracts abnormal protein synthesis, folding, and modification. Each UPR arm activates specific downstream transcription factors that are involved in the regulation of cellular proliferation, apoptosis, and protein translation pathways. 


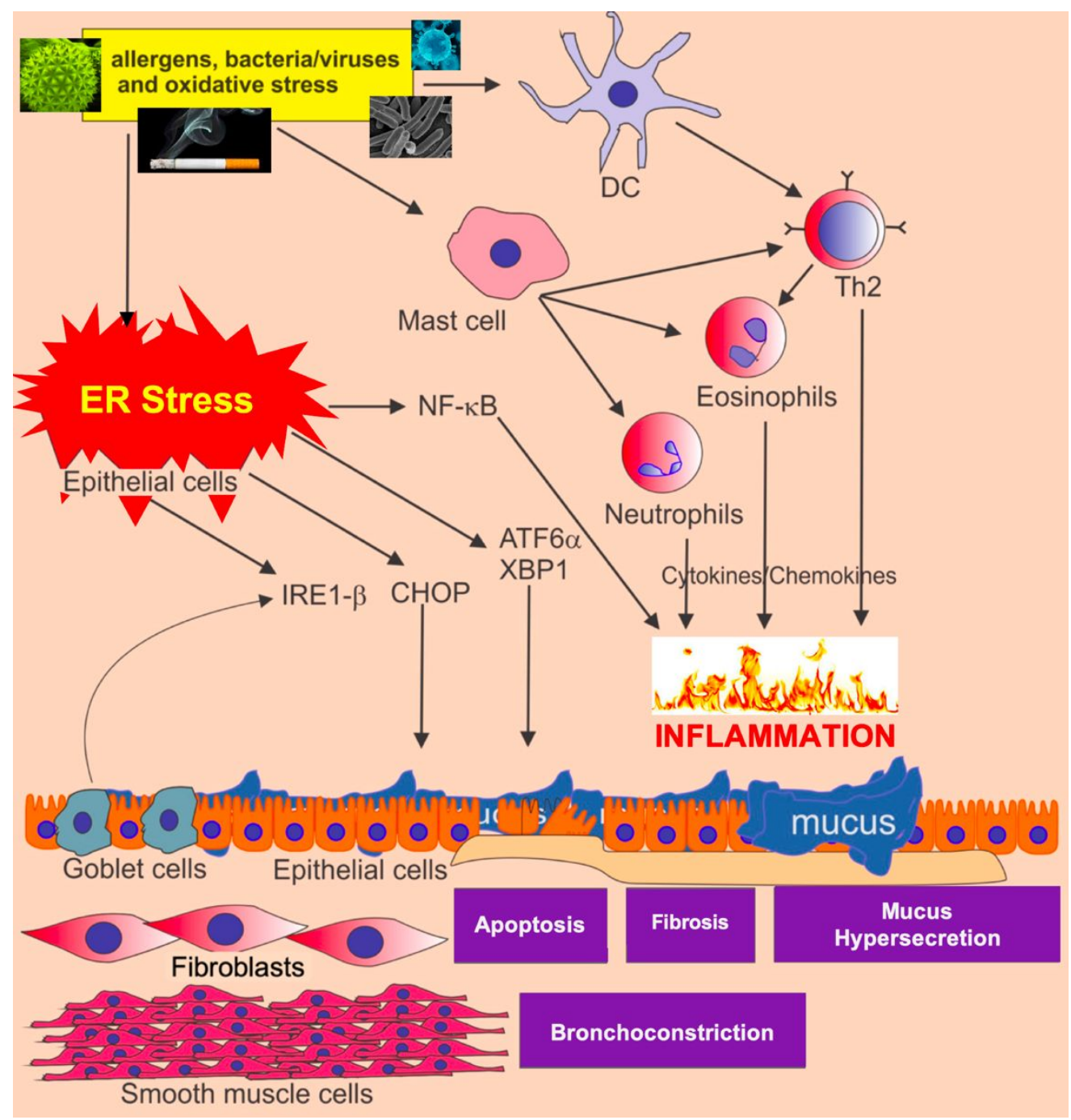

Figure 2. Asthma and UPR Crosstalk. Allergens and viral or bacterial infections induce eosinophilia and T helper type 2 (Th2 or type 2 ) inflammatory responses which could trigger asthma. Stimuli such as aeroallergens, oxidative stress, bacteria, pollutants, and viral infections can also disrupt ER integrity and act as inducers of ER. Pathogenic factors in asthma trigger ER stress and UPR pathways contributing to apoptosis and fibrosis in the lung. They also activate mast cells and Th2 cells to drive inflammation resulting in mucus hypersecretion, fibrosis, and bronchoconstriction following cytokine/chemokine release within the lung. Abbreviations: Dendritic cells (DCs), T helper (Th) cells, activating transcription factor-6 $\alpha$ (ATF6 $\alpha$ ), CCAAT/enhancer-binding protein (C/EBP) homologous protein (CHOP), Inositol-Requiring Enzyme-1 (IRE1), X-box-binding protein (XBP1), and Nuclear Factor Kappa B (NFאB). 